\title{
Comments on Statistical Issues in November 2013
}

Commentary

\section{Yong Gyu Park}

Department of Biostatistics, The Catholic University of Korea College of Medicine, Seoul, Korea

In this section, we explain the actual number of observations used in a multivariate analysis when one or more explanatory variables have missing values, which appeared in the articles titled, "Postmarketing surveillance study of the efficacy and safety of Phentermine in patients with obesity," by Kim et al. ${ }^{1)}$ and "Relationships between dietary habits and allostatic load index in metabolic syndrome patients," by Kim ${ }^{2)}$ published in September 2013.

\section{MISSING VALUES IN MULTIVARIATE ANALYSES}

When there are some missing values in one or more variables, most researchers choose one of the following strategies for analysis: 1) delete all observations which have missing values or 2) use all observations regardless of missing values. The

Table 1. Hypothetical data

\begin{tabular}{cccc}
\hline Response variable & \multicolumn{3}{c}{ Explanatory variables } \\
\hline $\mathrm{y}$ & $\mathrm{x} 1$ & $\mathrm{x} 2$ & $\mathrm{x} 3$ \\
\hline 1 & 1 & 1 & 1 \\
2 & 2 & 2 & 2 \\
3 & 1 & 1 & 2 \\
4 & 2 & 3 & 3 \\
5 & 3 & 2 & 3 \\
6 & 2 & 4 & 3 \\
7 & $\cdot$ & 3 & 4 \\
8 & $\cdot$ & 4 & 4 \\
9 & $\cdot$ & $\cdot$ & 4 \\
10 & & $\cdot$ & 4 \\
\hline
\end{tabular}

purpose of this section is to show how many observations are actually analyzed in multivariate analyses, such as multiple linear regression analysis or multiple logistic regression analysis, when there are different numbers of missing values in each explanatory variable. Let's perform a multiple linear regression using the following hypothetical data (Table 1).

In this data, explanatory variable $\mathrm{x} 1$ has four, $\mathrm{x} 2$ has two, and $\mathrm{x} 3$ has no missing values, respectively (denoted as a dot), and we will perform three analyzing processes using SPSS, 1) Pearson correlation analysis, 2) multiple linear regression analysis, and 3) stepwise multiple linear regression analysis.

\section{PEARSON CORRELATION ANALYSIS}

From the menus choose:

Analyze

Correlate

Bivariate...

Select all variables: $y, x 1, x 2, x 3$

We obtain the following results: (Table 2).

$\mathrm{X} 3$ has the highest correlation with $\mathrm{y}$, and explanatory variables, and $\mathrm{x} 1, \mathrm{x} 2$, and $\mathrm{x} 3$ are analyzed by using only their valid observations, 6, 8, and 10, respectively.

Table 2. Correlation coefficients

\begin{tabular}{|c|c|c|c|c|c|}
\hline & & $\mathrm{y}$ & $\mathrm{xl}$ & $\mathrm{x} 2$ & x3 \\
\hline \multirow[t]{3}{*}{$\mathrm{y}$} & Pearson correlation coefficients & 1 & 0.639 & 0.830 & 0.940 \\
\hline & P-value (two-sided) & & 0.172 & 0.011 & 0.000 \\
\hline & $\mathrm{N}$ & 10 & 6 & 8 & 10 \\
\hline
\end{tabular}




\section{MULTIPLE LINEAR REGRESSION ANALYSIS}

From the menus choose:

Analyze

$$
\text { Regression }
$$

Linear...

Choose dependent variable: $y$

Independent variables: $\mathrm{x} 1, \mathrm{x} 2, \mathrm{x} 3$

Options: statistics: descriptive statistics

We obtain the following results: (Tables 3-5).

$\mathrm{X} 3$ has the highest correlation with $\mathrm{y}$, but all analyses

Table 3. Descriptive statistics

\begin{tabular}{cccc}
\hline & Mean & SD & N \\
\hline $\mathrm{y}$ & 3.50 & 1.871 & 6 \\
$\mathrm{x} 1$ & 1.83 & 0.753 & 6 \\
$\mathrm{x} 2$ & 2.17 & 1.169 & 6 \\
$\mathrm{x} 3$ & 2.33 & 0.816 & 6 \\
\hline
\end{tabular}

(descriptive statistics, correlation analysis, and multiple regression analysis) are performed using only six observations which have no missing values for all dependent variables.

\section{STEPWISE MULTIPLE LINEAR REGRESSION ANALYSIS}

(Menus, variable selection, and options are the same as the above)

Variable selection methods: stepwise

We obtain the following results: (Tables 6-8).

Descriptive statistics (the same as above results)

Correlation coefficients (the same as above results)

Table 4. Correlation coefficients

\begin{tabular}{lccccc}
\hline & & $\mathrm{y}$ & $\mathrm{x} 1$ & $\mathrm{x} 2$ & $\mathrm{x} 3$ \\
\hline Pearson correlation & $\mathrm{y}$ & 1.000 & 0.639 & 0.777 & 0.917 \\
$\mathrm{~N}$ & $\mathrm{y}$ & 6 & 6 & 6 & 6 \\
\hline
\end{tabular}

Table 5. Coefficients

\begin{tabular}{|c|c|c|c|c|c|c|}
\hline \multirow{2}{*}{\multicolumn{2}{|c|}{ Model }} & \multicolumn{2}{|c|}{ Unstandardized coefficient } & \multirow{2}{*}{$\frac{\text { Standardized coefficient }}{\text { Beta }}$} & \multirow{2}{*}{$\mathrm{t}$} & \multirow{2}{*}{ Significance } \\
\hline & & Coefficient & SE & & & \\
\hline \multirow[t]{4}{*}{1} & Constant & -1.250 & 1.531 & & -0.816 & 0.500 \\
\hline & $\mathrm{xl}$ & -0.250 & 1.046 & -0.101 & -0.239 & 0.833 \\
\hline & $\mathrm{x} 2$ & 0.250 & 0.685 & 0.156 & 0.365 & 0.750 \\
\hline & $\mathrm{x} 3$ & 2.000 & 1.311 & 0.873 & 1.526 & 0.267 \\
\hline
\end{tabular}

Table 6. Entered/removed variables

\begin{tabular}{cccc}
\hline Model & Entered variable & Removed variable & Method \\
\hline 1 & $\mathrm{x} 3$ & $\cdot$ & Stepwise $($ criteria: enter $=0.050$, remove $=0.100)$ \\
\hline
\end{tabular}

Table 7. Analysis of variance

\begin{tabular}{ccccccc}
\hline & Model & Sum of square & Degrees of freedom & Mean square & F-ratio & Significance \\
\hline 1 & Regression & 14.700 & 1 & 14.700 & 21.000 & 0.010 \\
& Residual & 2.800 & 4 & 0.700 & & \\
Total & 17.500 & 5 & & & \\
\hline
\end{tabular}


Table 8. Coefficients

\begin{tabular}{|c|c|c|c|c|c|c|}
\hline & \multirow{2}{*}{ Model } & \multicolumn{2}{|c|}{ Unstandardized coefficient } & \multirow{2}{*}{$\frac{\text { Standardized coefficient }}{\text { Beta }}$} & \multirow{2}{*}{$\mathrm{t}$} & \multirow{2}{*}{ Significance } \\
\hline & & Coefficient & SE & & & \\
\hline \multirow[t]{2}{*}{1} & Constant & -1.400 & 1.122 & & -1.247 & 0.280 \\
\hline & $\mathrm{x} 3$ & 2.100 & 0.458 & 0.917 & 4.583 & 0.010 \\
\hline
\end{tabular}

From the total degrees of freedom $(\mathrm{df}=5)$ in the analysis of variance table, a stepwise multiple regression analysis is performed using only six observations which have no missing values for all explanatory variables, even though the results show that only one variable, $x 3$, which has no missing values, remains in the final model.

As we can see from the above three results, the actual number of observations analyzed in a multivariate analysis is the minimum number of valid observations of all explanatory variables we had intended to include in the analysis, regardless of the variable selection methods.

\section{CONFLICT OF INTEREST}

No potential conflict of interest relevant to this article was reported.

\section{REFERENCES}

1. Kim HO, Lee JA, Suh HW, Kim YS, Kim BS, Ahn ES, et al. Postmarketing surveillance study of the efficacy and safety of phentermine in patients with obesity. Korean J Fam Med 2013;34:298-306.

2. Kim JY. Relationships between dietary habits and allostatic load index in metabolic syndrome patients. Korean J Fam Med 2013;34:334-46. 